\title{
Analysis of Solar PV Application Based on Bidirectional Inverter
}

\author{
Maideen Abdhulkader Jeylani $\mathrm{A}^{1 *}$, Kanakaraj $\mathrm{J}^{2}$, Mahaboob Subahani $\mathrm{A}^{3}$, Rameshkumar $\mathrm{K}^{4}$ \\ ${ }^{1,4}$ Dept of EEE, Sri Krishna College of Engineering and Technology, Coimbatore \\ ${ }^{2}$ Dept of EEE, PSG college of Technology, Coimbatore \\ ${ }^{3}$ Dept of EEE, PSG college of Technology, Coimbatore
}

\begin{abstract}
Building a DC-DC converter with high step-up, low cost and high efficiency from low DC voltage is the requirement in many applications. It is achieved by employing a front end boost converter based full bridge inverter on bidirectional inverter. In conventional boost converter during device turn-off, voltage overshoot occurs across the semiconductor devices. So, an additional snubber or voltage clamping is required to limit the overshot voltage. It upturns the component's count and losses making the converter less efficient. The above problem can be avoided by operate the converter with soft-switching method by using secondary modulation technique. Hence, it avoids the need of additional snubber or auxiliary circuit. Soft switching operation is proposed in the bidirectional inverter. Soft switching operation is achieved through the auxiliary circuit, which consist of two auxiliary switches, Front end converter and full bridge inverter. Bidirectional inverter allows current flow in both direction and therefore permits energy flow from the grid to storage when solar energy is not available. The theoretical analysis of the proposed converter is verified using simulation results.
\end{abstract}

Keywords -Boost converter, soft switching, and Frontend converter

\section{Introduction}

The conventional power generation method faces problems like depletion of fossil fuels and polluting the environment. Also because of increasing demand and energy crisis, world's power production has shifted hugely towards renewable energy system. Additionally, the source is freely available and is pollution free. Solar PV is one of the fast growing methodologies among the renewable energy systems accounting for $1 / 3$ of the world's power production by 2030 . The boost converter is the preferred choice in earlier days because of its high voltage gain and simple circuit structure. But the power level is limited due to hard switching operation which also increases switching losses leading to less efficiency.

\footnotetext{
* Corresponding author: jeylani7862@gmail.com
} 
The aim of this paper is to achieve soft switching (ZCS of primary side and ZVS of secondary side) of all semiconductor devices. The objective of this project is to provide an efficient DC-DC conversion in Residential solar power system. Bidirectional dc/dc*

Converters are classified into two types, isolated and non-isolated, isolated bidirectional uses high frequency transformers and provide isolation between battery and load. But isolated bidirectional dc/dc converters are bulky and have low efficiency. This paper is used as a reference for understanding the benefits of soft-switching and the method of attaining it. [1]

Security enriched high step-up DC-DC converter for AC photovoltaic module solicitation was proposed. To protect installers and users from electrical hazards Chen proposed a converter that employs floating active switch to isolate energy from the PV panel when the AC module is off. This paper is used as a reference for achieving high step-up voltage conversion ratio, without extreme duty ratio and the numerous turns- ratios of a coupled inductor. [2].The development of a high efficiency bidirectional converter for power sources with great voltage diversity was focused. This paper is used as a reference for mitigating the switching losses by employing transformer based circuit topologies and frequently applying soft switching techniques including zero voltage switching (ZVS) or zero current switching (ZCS). The techniques of voltage clamping, synchronous rectification and soft switching are manipulated thus providing high efficiency bidirectional power conversion for power sources with large voltage diversity. [3]

\section{Proposed topology}

The proposed block diagram is shown in fig. 1. The system consists of two inputs such as solar (PV) system and battery backup. Solar pv is connected to dc to dc converter. Extracting the energy level as more than input level dc-dc converter will be used. Energy extracted from solar panel will be given to ac load at the same time battery get loaded with the backup energy. Suppose energy from solar panel deactivated means power to ac load given by back up energy. Suppose the energy extracted from solar panel and the battery will be stopped means battery gets reloaded by energy from ac load.

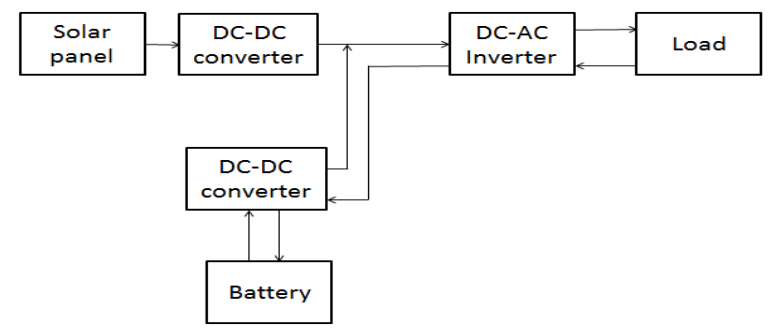

Fig.1. Block diagram of the proposed system.

In this paper, a two-stage dc/ac inverter is proposed for the PV residential power system, as shown in fig.2. Which is composed of a novel high-step-up snubber less full bridge front-end converter and a standard full-bridge inverter. The shunt capacitors C1-C6 and the shunt body diodes D1-D6are the parasitic drain-to-source capacitance and body diodes of the MOSFETs, respectively. The shunt capacitors $\mathrm{C} 7-\mathrm{C} 10$ are the parasitic capacitance, and shunt diodes D7-D10 are the external diodes connected to the insulated-gate bipolar transistors. The proposed inverter is bidirectional and therefore permits energy flow from the grid to storage when solar energy is not available. The proposed two-stage dc/ac inverter includes with closed loop control as shown in fig. 2. A closed controller is proposed to regulate the output 
voltage. The inductor current is able to change more quickly than the output voltage. Inverter is bidirectional and therefore permits energy flow from the grid to storage when solar energy is not available.

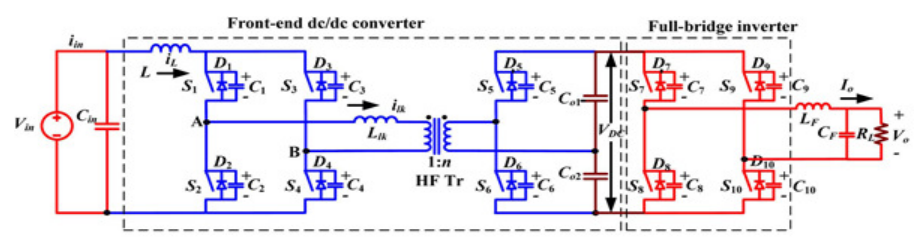

Fig. 2. Circuit diagram of the proposed system.

\section{Design of the converter}

1) Average Input Current :

$$
\operatorname{Iin}=\frac{P_{0}}{v_{\text {in }}}=10.52 \mathrm{~A}
$$

2) Maximum Voltage Across the Primary Switch:

$$
V P, S W=\frac{v_{i n}}{2 n}=6 \mathrm{~V}
$$

3) Voltage conversion ratio or input and output voltage:

$$
V D C=\frac{n * v_{i n}}{2(1-d)}=300 \mathrm{~V}
$$

4) Leakage inductance of the transformer or series inductance Llk is calculated using the following equation:

$$
L l k=\frac{v_{0}(d-0.5)}{2 * n * I_{i n} * f s}=0.427 u
$$

5) The RMS current through the primary switches of the front-end converter is given by

$$
I p, r m s=I_{\text {in }} \frac{\sqrt{2-d}}{3}=6.65 \mathrm{~A}
$$

6) The RMS current through the primary winding of the HF transformer is given by

$$
I l k, r m s=I_{\text {in }} \frac{\sqrt{5-4 d}}{3}=8.14 \mathrm{~A}
$$

7) The value of the boost inductor is given by

$$
L=\frac{V_{i n} *(d-0.5)}{\Delta * I_{i n} * f S}=0.0079 \mu \mathrm{H}
$$

8) The RMS current through secondary-side switches is given by

$$
I a v=\frac{P_{O}}{2 V_{o}}=0.466 \mathrm{~A}
$$

9) Average current through the anti-parallel body diodes of secondary devices is given by

$$
I D=\frac{I_{\text {in }} *(7-6 d)}{8 n}=0.28 A
$$

10) RMS current through the secondary side switches is given by

$$
I s, r m s=\frac{I_{i n}}{2 n} \frac{\sqrt{2 d-1}}{3}=0.23 \mathrm{~A}
$$

11) VA rating of $\mathrm{HF}$ transformer is given by

$$
\operatorname{Vax}-\max =\frac{V_{o^{*} I_{\text {in }}}}{n} \frac{\sqrt{2(5-4 d) *(1-d)}}{3}=151.4 \mathrm{~V}
$$




\section{Simulation results}

The proposed topology is simulated in MATLAB Simulink for the designed values and Constant DC output voltage is obtained. Performance analysis for the open loop and closed loop circuit is done from which it can be seen that Front End Rectifier and full bridge inverter

Table 1. Simulation Parameters.

\begin{tabular}{|c|c|c|c|}
\hline \multirow{2}{*}{ S.NO } & \multicolumn{3}{|c|}{ Parameters values and unit } \\
\cline { 2 - 4 } & Variables and parameters & Value & Unit \\
\hline 1 & Input Voltage & 28 & $\mathrm{~V}$ \\
\hline 2 & Switching Frequency & 50 & $\mathrm{~Hz}$ \\
\hline 3 & Output power & 280 & $\mathrm{~W}$ \\
\hline 4 & Leakage Inductance & 0.427 & $\mathrm{uH}$ \\
\hline
\end{tabular}

The simulations for proposed circuit is simulated The inverter is simulated using simulation software MATLAB SIMULINK .The simulation are done using values Vs=28V and switching frequency of 50Khz.The output voltage are observed. System model of proposed inverter is simulated using MATLAB SIMULINK is shown in fig.3.
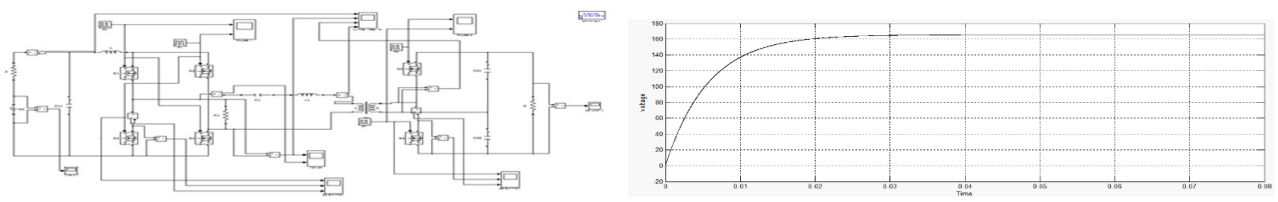

Fig. 3. MATLAB simulation for proposed circuit Fig.4. Output voltage

The power supply module must convert $28 \mathrm{~V}$ input to $165 \mathrm{~V}$ output voltage. The output voltage of the converter is observed as follows. Output voltage observed in simulation is as shown in fig.4. Boost mode process change according to the dc link output voltage. The operation mode change to boost from when the dc link voltage reaches the lower limit. Correspondingly boost to operation happens when the output dc link voltage reaches the upper limit. Current flows through main inductor directionally for charging the dc link voltage. This will be shown in the open loop simulation Fig.3. The simulations for proposed closed loop circuit are simulated. Closed loop control is simulated using simulation software MATLAB SIMULINK .The simulation are done using values $\mathrm{Vs}=28 \mathrm{~V}$ and switching frequency of $50 \mathrm{kHz}$.The output voltage System model of proposed closed loop is simulated using MATLAB SIMULINK is shown in fig.5.

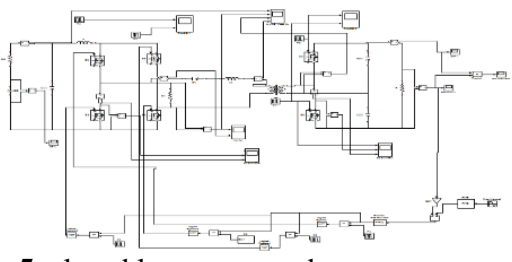

Fig.5. closed loop proposed system

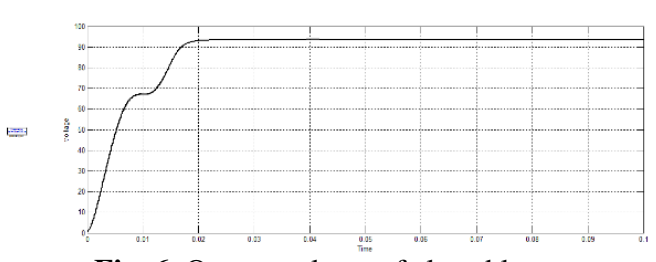

Fig .6. Output voltage of closed loop system

The overall block diagram Fig.1 has three modes of operation .it also has to be simulated in simulation software MATLAB SIMULINK 


\section{Mode 1:}

In mode 1 the input will be extracted from solar panel and it will be reloaded into load as well as battery backup. The simulation are done using values input dc voltage $40 \mathrm{~V}$, output dc voltage $240 \mathrm{~V}$

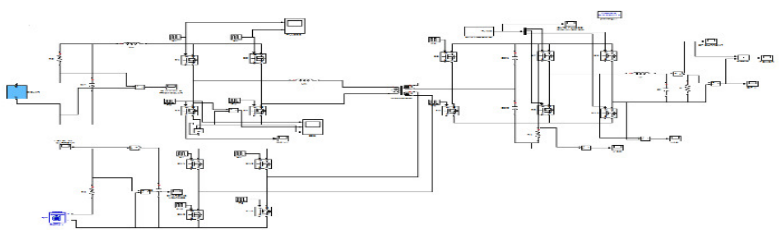

Fig .7. Mode 1 Simulink model

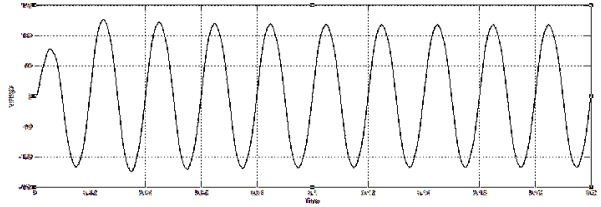

Fig .8. Mode 1 output voltage

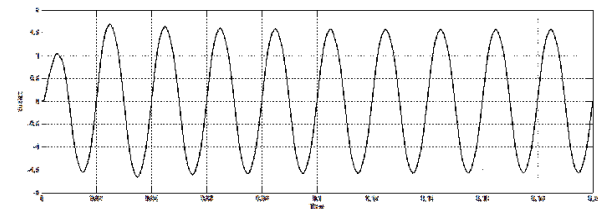

Fig .9. Mode 1 output current

\section{Mode 2:}

In mode 2 the source will be terminated and the energy transferred to load is gain from battery backup energy (battery).Input dc voltage (Battery) 42V and Output voltage 120V

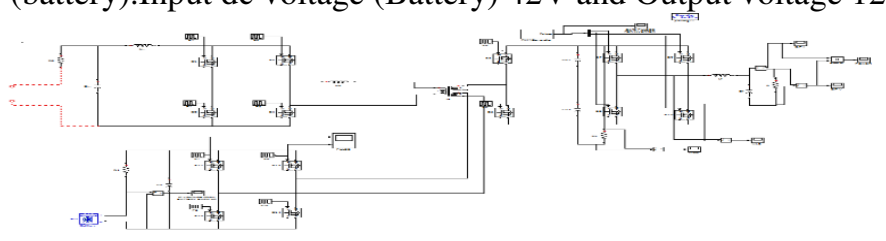

Fig .10. Mode 2 Simulink model

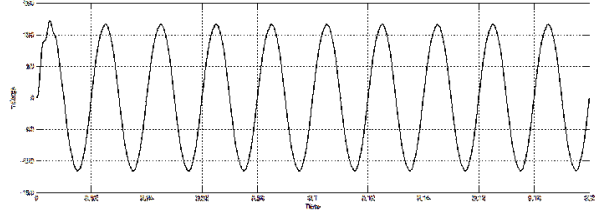

Fig .11. Mode 2 output voltage

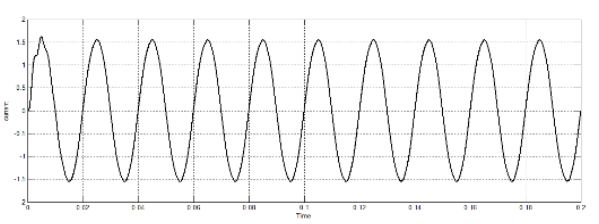

Fig .12. Mode 2 output current

\section{Mode 3:}

In mode 3 Energy transferred from load (AC) from that both back up and source absorb energy. Input Voltage (AC load $200 \mathrm{~V}$. Charging voltage (i/p \& backup) 31V. mode 3 is simulated using simulation software MATLAB SIMULINK

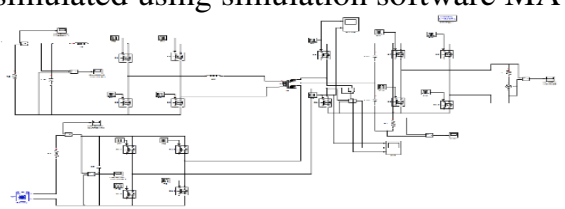

Fig.13. mode 3 Simulink model

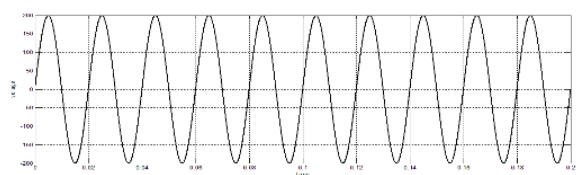

Fig.14. mode 3 output voltage 


\section{Conclusion}

This paper has presented the implementation of analysis of solar pv application based bidirectional inverter. The proposed innovative secondary modulation achieves the softswitching of all semiconductor devices (ZCS of primary side and ZVS of secondary devices) without modifying the topology. Switching losses are condensed ominously due to ZCS of primary switches and ZVS of secondary switches. In addition, soft switching is inherent, independent of the load and is maintained with variation in source voltage. Soft switching permits high switching frequency operation leading to design compact, low cost, light weight system and high efficiency over wide range of load and input voltage. Stability is maintained by use of closed loop control operation. However future work and research is still needed in this closed loop designing process.

\section{References}

1. S. J. Young, S. C. Shin, J. H. Lee, Y. C. Jung and C. Y. Won, IEEE Trans. Power Electron., vol. 29, (2014)

2. L. Zhang, K. Sun, Y. Xing, and M. Xing, IEEE Trans. Power Electron. vol. 29, no. 3, pp. 1229-1238, (Mar. 2014)

3. Y. Zhou, W. Huang, P. Zhao, and J. Zhao, IEEE Trans. Power Electron., vol. 29, no. 3, pp. 3317-3328, (2014)

4. P.xuewei, U.R.Prasanna, and A.K.Rathore, IEEE Trans, Power Electron, vol. 28, no. 7, pp. 3317-3328, (2013)

5. S. M. Chen, T. J. Liang, L. S. Yang and J. F. Chen, IEEE Trans, vol. 27, no. 4, pp. 1809 -1817, Apr. (2012)

6. M. Cacciato, A. Consoli, R. Attanasio, and F. Gennaro, IEEE Trans. Ind. Electron., vol. 57, no. 5, pp. 1678-1686, May (2010)

7. Z. Zhang, O. C. Thomsen, and M. A. E. Andersen, IEEE Trans. Ind. Electron, vol. 59, no. 7, pp. 1915-1922, Jul. (2010)

8. R. J. Wai and R. Y. Duan IEEE Trans. Power Electron, Vol. 22, no. 5, pp. 1986-1996, Sep. (2007)

9. G. Yao, Y. Deng, and X. He, in Proc. IEEE 37th Power electron spec Conf., A ZVT PWM pp. 1-5. Aug. (2016)

10. R. J. Wai and R. Y. Duan, IEEE Trans. Power vol. 20, no. 4, pp. 847-856, Jan. (2018)

11. Q. Zhao and F. C Lee, IEEE Trans. Power Electron., vol. 18, no. 1, pp. 65-73, Jul. (2016) 